\section{Evaluation of air quality index for air quality data interpretation in Delhi, India}

\author{
Sanjoy Maji ${ }^{1}$, Sirajuddin Ahmed ${ }^{1, *}$, \\ Santu Ghosh ${ }^{2}$ and Saurabh Kumar Garg ${ }^{3}$ \\ ${ }^{1}$ Faculty of Engineering and Technology, Jamia Millia Islamia, \\ Delhi 110 025, India \\ ${ }^{2}$ Department of Biostatistics, St. Johns Medical College, \\ Bengaluru 560 034, India \\ ${ }^{3}$ AL-FALAH University, Dhauj, Faridabad, Haryana 121 004, India
}

Metro cities across the world use air quality index (AQI) as a tool for local air quality management. The basic purpose of the AQI system is to interpret the air quality status based on potential human health impacts. In the air quality indexing system, ranges of air pollutant concentration are characterized into different categories of air quality on the basis of health implication criteria. Standardized public health advisories are used for different categories of air quality for general public awareness. AQI values at the regional level are normally reported in the media to enhance public access and awareness. In the present study, air quality of Delhi, India has been interpreted, and seasonal and spatial deviation of air quality mapped to enable health risk communication. We also highlight the linkage of air quality with daily nontrauma mortality rate. A significant correlation of air quality with daily non-trauma death rate was observed. The female population was found to be more vulnerable to poor air quality in comparison to the males. Among the different age groups, maximum vulnerability was observed for the population aged 65 years and above. Average air quality status of Delhi was observed at a level which can cause breathing uneasiness to those with respiratory comorbidities, as well as for children and aged people. Direct linkages of different air pollutants with associated health impact estimates have been worked out by several researchers in the past. The present study evaluates the effect estimates on daily non-trauma mortality values with AQI levels. The findings of this study are consistent with earlier reports and provide additional evidence for health impact linked to poor air quality.

Keywords: Air quality, metro cities, public awareness, respiratory health.

NowADAYS, the general public is becoming more concerned about the ill-effects and health disorders due to air pollution. Daily updated air pollution information has become one of the basic tools to increase public awareness of the harmful effects of poor air quality. The ambient air quality and its effects on the health of people and the environment are among the important topics of concern across the world.

*For correspondence. (e-mail: sirajuahmed@rediffmail.com)
A wide range of literature has recognized the association of exposure to air pollutants and the associated illhealth, such as increased hospital admission rates with respiratory and cardiovascular comorbidities and congestive heart failure, increase in the incidences of asthma attacks, acute bronchitis and decreased lung function ${ }^{1-5}$. Indoor and outdoor air pollution are among the top environmental health risk factors. According to the estimates of the World Health Organization (WHO), air pollution is accountable for 7 million premature deaths in the world ${ }^{6}$.

A few human health impact studies of air pollution have been conducted in India ${ }^{7-12}$. An estimated 1.09 million deaths are attributable to air pollution in the country ${ }^{13}$. A report on 'Medical Certification of Cause of Death' by the Directorate of Economics and Statistics, Government of the National Capital Territory (NCT) of Delhi ${ }^{14}$ shows respiratory and circulatory diseases among the principal reasons of death in Delhi. Figure 1 shows the trend of mortality due to respiratory and circulatory diseases in Delhi for the period 2002-12. Due to nonattainment of National Ambient Air Quality Standards (NAAQS) under the National Air Quality Monitoring Programme (NAAQMP), the Central Pollution Control Board (CPCB), Government of India (GoI) had included 95 cities in the list of polluted cities on ambient air quality data obtained during 2008-2010 (http://cpcbenvis.nic. in/airpollution/finding.htm). Though several locations in India are in the list of polluted places of the world ${ }^{15}$, there is lack of awareness on air quality data interpretation.

Nowadays, regular updates on air quality asserting the complex connection between exposure to air pollutants and ill-health have become a tool of air pollution information system for protecting public health. Simple comparison of air pollutant concentration values with NAAQS interpret air quality as acceptable or not with respect to standards. However, the air quality index (AQI) system defines index values based on probable health and environmental implications of particular air pollutant concentration levels, so as to enable health risk communication of air quality. AQI integrates numerous diverse measurements of air pollutant concentration into

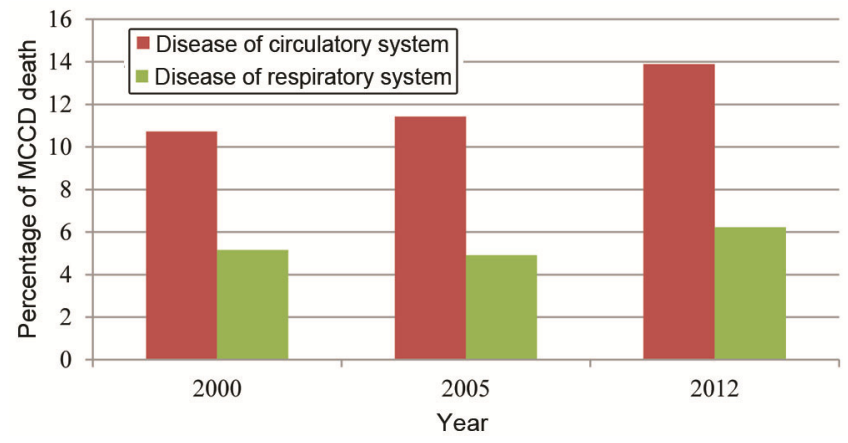

Figure 1. Percentage of death due to respiratory and circulatory diseases in Delhi, India for the period 2000-2012. 


\section{RESEARCH COMMUNICATIONS}

Table 1. United States Environmental Protection Agency air quality criteria and associated health communication

\begin{tabular}{|c|c|c|}
\hline $\begin{array}{l}\text { Air quality index } \\
\text { values (AQI) }\end{array}$ & Health criteria & Health communication \\
\hline $0-50$ & Good & \\
\hline $51-100$ & Moderate & Sensitive populations are at risk of respiratory disease. \\
\hline $101-150$ & Unhealthy for sensitive groups & $\begin{array}{l}\text { Likely risk of breathing uneasiness in vulnerable groups; } \\
\text { exacerbation of respiratory comorbidity and premature mortality } \\
\text { in vulnerable groups. }\end{array}$ \\
\hline $151-200$ & Unhealthy & $\begin{array}{l}\text { Exacerbation of respiratory comorbidity and premature mortality in } \\
\text { vulnerable populations; aggravated respiratory symptoms in } \\
\text { general public. }\end{array}$ \\
\hline $201-300$ & Very unhealthy & $\begin{array}{l}\text { Vulnerable populations should avoid outside physical activity. } \\
\text { General public should escape longtime exposure. }\end{array}$ \\
\hline $301-500$ & Hazardous & $\begin{array}{l}\text { All should escape any physical activity outside; vulnerable people } \\
\text { should be inside their homes and maintain minimum activity. }\end{array}$ \\
\hline
\end{tabular}

Table 2. Indian air quality index criteria and associated health communication

\begin{tabular}{lll}
\hline AQI value & Health criteria & \\
\hline $0-50$ & Good & Negligible impact \\
$51-100$ & Satisfactory & Slight breathing uneasiness in vulnerable people \\
$101-200$ & Moderate & Breathing uneasiness in populations with respiratory comorbidity, kids and the aged \\
$201-300$ & Poor & Breathing uneasiness in the population on long exposure \\
$301-400$ & Very poor & Respiratory diseases on long exposure \\
$>400$ & Severe & Respiratory problems even in the healthy population \\
\hline
\end{tabular}

a standard indicator, so that it enables the public to understand the associated environmental and health implications of air pollutant concentration levels on a daily basis. This type of health risk communication have several goals; to enable the public to assess the likely health effects associated with particular levels of pollutant concentration, to increase awareness to avoid activities that support air pollution, to inform the vulnerable populations, like those affected by respiratory diseases to take precautionary measures and to study pollution drifts and increase awareness among the general public on health affects due to air pollution.

Four key parameters form the base in the design of an AQI system. These are selection of pollutants, relationship of exposure-response functions, suitable descriptors defining the risk levels and, most importantly, selection of a methodology or algorithm for calculating the index value in case of simultaneous exposure to various pollutants. In fact, diverse AQI systems are followed worldwide. The AQI system developed by (United States Environmental Protection Agency, US-EPA) is widely used to report air quality in different parts of the world. The US-EPA-AQI integrates five important air pollutant concentration data, viz. particulate matter $\left(\mathrm{PM}_{10}, \mathrm{PM}_{2.5}\right)$, sulphur dioxide $\left(\mathrm{SO}_{2}\right)$, ozone $\left(\mathrm{O}_{3}\right)$, nitrogen dioxide $\left(\mathrm{NO}_{2}\right)$ and carbon monoxide $(\mathrm{CO})$. The pollutant concentrations are distributed in the index range from 0 to 500 with six sub-indices corresponding to potential health and environmental impacts ${ }^{16}$ (Table 1).
In India, the concept of air quality interpretation using the AQI system is relatively new; the AQI system for the country was introduced in 2014. Similar to the US-EPAAQI system, the Indian AQI (IND-AQI) system also identifies six categories of air quality. However, subindex categories and their associated health impact statements represent a different risk category to calculate the index scale $^{17}$. Table 2 shows the IND-AQI air quality criteria and related health communications.

Delhi, one of the largest megacities of India, is counted among the most severely polluted megacities in terms of air pollution ${ }^{18}$. During episodic events, the concentration of air pollutants often crosses the air quality standards by 3-4 times ${ }^{19}$. Delhi, having extremely high levels of air pollutant concentration and high temporal variation of air quality due to seasonal fluctuations, represents almost all of the air quality classes of the AQI sub-index scale. In an earlier study, we have interpreted air quality of Delhi using the US-EPA AQI method ${ }^{20}$. The aim of the present study is to compare air quality interpretation of Delhi using the AQI system proposed by the US-EPA and the CPCB, GoI. The study also estimates the impact on daily mortality rate with AQI sub-index values. Spatial as well as seasonal variation of air quality was also examined.

Delhi, a northern Indian city is spread over, $28^{\circ} 52.6^{\prime}-$ $28^{\circ} 24.7^{\prime} \mathrm{N}$ lat. and $76^{\circ} 50.28^{\prime}-77^{\circ} 19.06^{\prime} \mathrm{E}$ long., at an average elevation of about $216 \mathrm{~m}$. The area of the city is approximately $1483 \mathrm{sq}$. $\mathrm{km}$ with almost equal proportion 
of urban and rural parts. The general climate is characterized by extreme hot and dry weather during summer season, whereas intense cold weather is observed during winter. The temperature reaches up to $45^{\circ} \mathrm{C}$ during summer, whereas average winter temperature is about $4^{\circ} \mathrm{C}$. Delhi has four distinct seasons, viz. winter (December to February), summer (March to June), rainy season (July to September), and post monsoon season (October to November). Population density is very high with 11,320 per sq. $\mathrm{km}$ against the national average of 382 per sq. $\mathrm{km}$ (ref. 21). Administratively, Delhi has nine districts, namely Northwest Delhi, North Delhi, Northeast Delhi, East Delhi, New Delhi, Central Delhi, West Delhi, Southwest and South Delhi. Table 3 shows the demographic outline of Delhi according to the 2011 census $^{22}$.

The CPCB, GoI is the central agency for air quality measurements in Delhi. There are nine air quality monitoring stations (AQMS) operated by CPCB, viz. Pitampura, Janakpuri, Siri Fort, Nizamuddin, Town Hall, NY School, Mayapuri, Shahzada Bagh, and Shahdara. Daily records of $\mathrm{PM}_{10}, \mathrm{NO}_{2}$, and $\mathrm{SO}_{2}$ were obtained from CPCB, GoI, for the period 2008-2010. The AQMS follow the existing protocol of two-sample collection in a week at equal intervals with maximum 104 samples from each AQMS in a year. Table 4 shows the salient features of AQMS while Figure 2 shows their locations.

The daily counts of non-trauma death data of Delhi for the period 2008-2010 were obtained from the Department of Economics and Statistics, Government of Delhi.

According to the protocol under NAAQMP, the monitoring stations are operated twice a week and record maximum 104 readings from individual monitoring stations in a year. Air pollutant concentration of the

Table 3. Demographic profile of Delhi city

\begin{tabular}{lccc}
\hline Age strata (years) & $\begin{array}{c}\text { Population } \\
\text { (million) }\end{array}$ & $\begin{array}{c}\text { Males } \\
\text { (million) }\end{array}$ & $\begin{array}{c}\text { Females } \\
\text { (million) }\end{array}$ \\
\hline $0-4$ & 0.13 & 0.07 & 0.06 \\
$5-44$ & 0.12 & 0.065 & 0.56 \\
$45-64$ & 0.26 & 0.14 & 0.12 \\
$\geq 65$ & 0.06 & 0.03 & 0.03 \\
Total population & 16.79 & 8.99 & 7.80 \\
\hline
\end{tabular}

Table 4. Details of air quality monitoring stations of Delhi operated by the Central Pollution Control Board

\begin{tabular}{lll}
\hline Location & \multicolumn{1}{c}{ Type } & \multicolumn{1}{c}{ Area } \\
\hline Nizamuddin (A1) & Residential & South Delhi \\
Shahzada Bagh (A2) & Industrial & Northwest Delhi \\
Shahdara (A3) & Industrial & East Delhi \\
Janakpuri (A4) & Residential & West Delhi \\
Siri Fort (A5) & Residential & South Delhi \\
N.Y. School (A6) & Residential & Southwest Delhi \\
Town Hall (A7) & Residential & Central Delhi \\
Mayapuri (A8) & Industrial & Southwest Delhi \\
Pitampura (A9) & Residential & Northwest Delhi \\
\hline
\end{tabular}

missing monitoring days was generated through locally weighted scatter-plot smoother (LOESS) function for the different AQMS. LoESS regression is a non-parametric method where least squares regression is performed to smoothen a volatile time series ${ }^{23}$. Average daily exposure data for Delhi were estimated through averaging air quality parameter values from all individual AQMS.

The ambient monitoring data of the criteria pollutants which give the highest index value are considered for overall assessment of a given day's air quality. The following mathematical expression was used for AQI calculation

$$
I=\frac{I_{\mathrm{high}}-I_{\text {low }}}{C_{\mathrm{high}}-C_{\mathrm{low}}}\left(\mathrm{C}-\mathrm{C}_{\mathrm{low}}\right)+I_{\mathrm{low}},
$$

where $I$ is the index value, $C$ the recorded pollutant concentration, $C_{\text {low }}$ the index scale concentration value that is $\leq C, C_{\text {high }}$ the index scale concentration value that is $\geq C$, $I_{\text {low }}$ the index scale value equivalent to $C_{\text {low }}$ and $I_{\text {high }}$ is the index scale value equivalent to $C_{\text {high }}$.

Air quality data of Delhi were interpreted using the above-mentioned equation with the respective air quality class and sub-index values of both the US-EPA-AQI and IND-AQI systems. Spatial deviation of air quality was also observed by calculating the AQI sub-index for individual monitoring stations. To study temporal variation, air quality of Delhi was compared for the following four seasons, viz. rainy season (July-September), summer (March-June), post-monsoon season (October-November) and winter (December-February).

The AQI values provide the overall characteristics of any given day's air quality based on its health criteria.

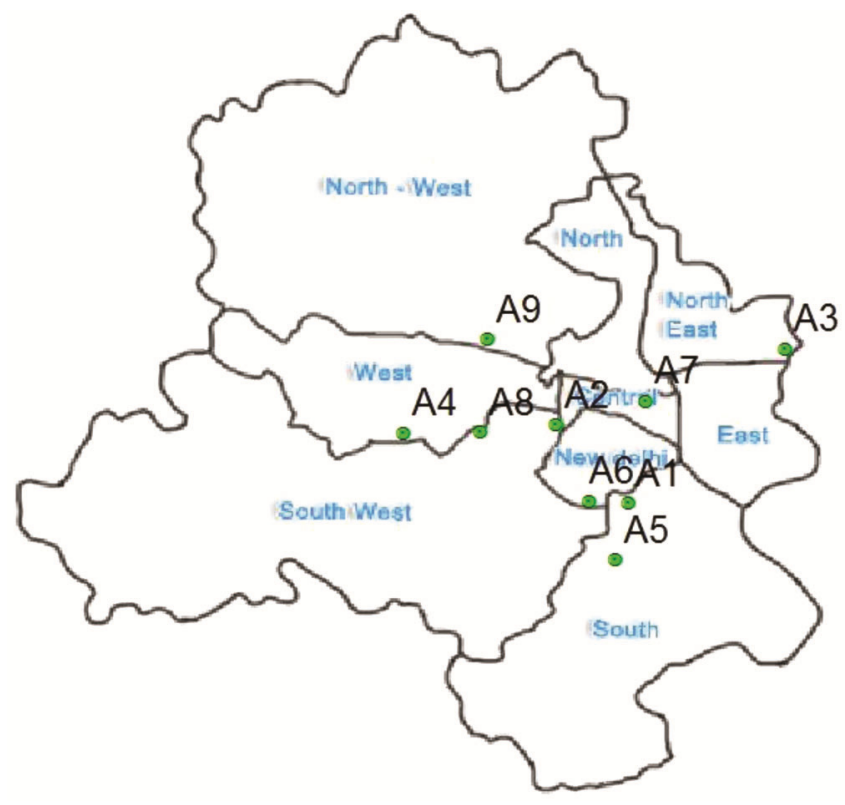

Figure 2. Air Quality Monitoring Stations (AQMS) superimposed on the map of Delhi. 
Table 5. Comparison of interpretation of air quality according to India-AQI (IND-AQI) and US-EPA-AQI systems

\begin{tabular}{lcllc}
\hline \multicolumn{2}{c}{ IND-AQI } & & \multicolumn{2}{c}{ US-EPA-AQI } \\
\cline { 1 - 1 } \cline { 5 - 6 } Category & Percentage & & Category & Percentage \\
\hline Good & 0 & & Good & 0.0 \\
Satisfactory & 0.0 & & Moderate & 14.0 \\
Moderate & 49.6 & & Unhealthy for sensitive groups & 37.1 \\
Poor & 46.4 & & Unhealthy & 46.6 \\
Very poor & 3.8 & & Very unhealthy & 2.2 \\
Severe & 0.1 & & Hazardous & 0.1 \\
\hline
\end{tabular}

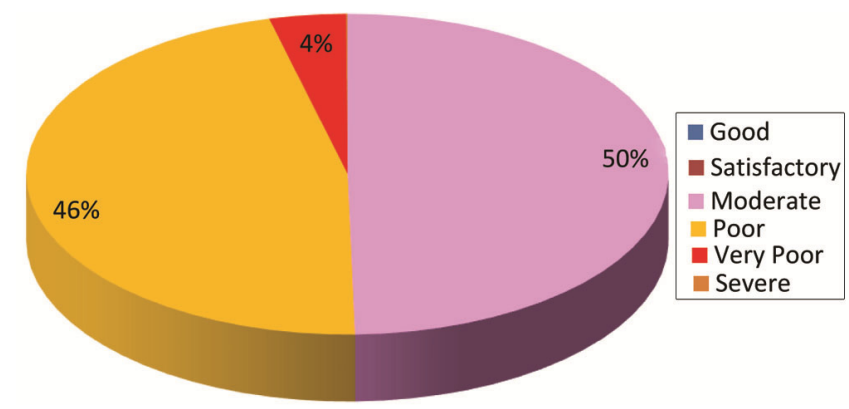

Figure 3. Frequency distribution of AQI sub-index categories according to the IND-AQI system.

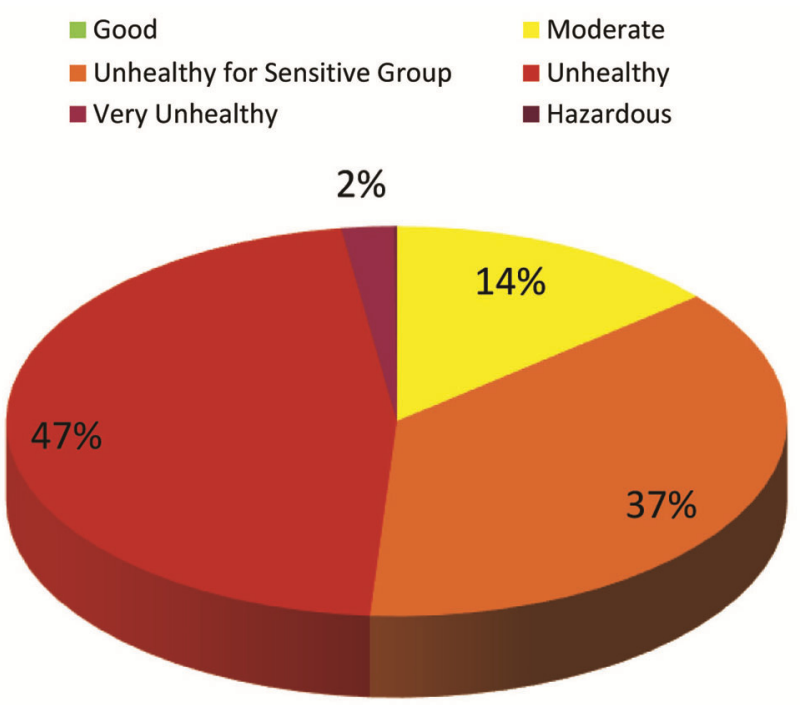

Figure 4. Frequency distribution of AQI sub-index categories according to the US-EPA AQI system.

Higher values of AQI indicate that many people are exposed to a high degree of pollution level and are susceptible to adverse health impacts. The generalized linear model (GLM) is widely used for assessing the association of environmental exposure with health outcome ${ }^{24}$. Where the resultant variable denotes count data (e.g. number of daily non-trauma mortalities), the model expression is characterized by Poisson regression. The resultant variable is supposed to follow Poisson distribution and is expressed by a linear combination of environmental explanatory variables using a log function. The GLM with Poisson regression was used to link the daily AQI values with response variables (number of daily non-trauma mortalities).

Daily AQI sub-index values were calculated following the IND-AQI and US-EPA-AQI systems. Table 5 shows a comparison of frequency distribution of different air quality categories according to both systems. Figures 3 and 4 show the frequency distributions of AQI sub-index categories according to the IND-AQI and US-EPA-AQI system respectively.

The observable differences between the IND-AQI and US-EPA-AQI systems are built into the safety factor for sub-index categorization. The IND-AQI system classifies sub-index categories as 'good' (AQI: 0-50), 'satisfactory' (AQI: 51-100), 'moderate' (AQI: 101-200), 'poor' (AQI: 201-300), 'very poor' (AQI: 301-400) and 'severe' (AQI: 401-500), whereas the US-EPA-AQI system has sub-index categories as 'good' (AQI: 0-50), 'moderate' (AQI: 51-100)', 'unhealthy for sensitive groups' (101150), 'unhealthy' (AQI: 151-200), 'very unhealthy' (AQI: 201-300) and 'hazardous' (AQI: >300). The most striking difference between both systems is that in the US-EPA-AQI system, the sub-indices range category for AQI 101-200 has been divided into two different air quality categories with AQI 101-150 representing 'unhealthy for sensitive groups' and AQI 151-200 representing 'unhealthy' for the general population; whereas the IND-AQI system marks the respective sub-index range of AQI 101-200 as 'moderate' category only.

Air quality data interpretation according to the INDAQI system places the predominant air quality in the 'moderate' category followed by 'poor', whereas the US-EPA AQI system shows a predominant frequency class of 'unhealthy' followed by 'unhealthy for sensitive groups' categories.

It is to be noted here that gaseous pollutant concentrations were below the threshold value, whereas particulate matter (PM) was the only criteria pollutants in the determination of AQI sub-indices for all AQMS. Figure 5 shows sub-index categories and their associated health effect statements for respirable suspended particulate matter (RSPM) for the IND-AQI and US-EPA-AQI system respectively. 
(a)
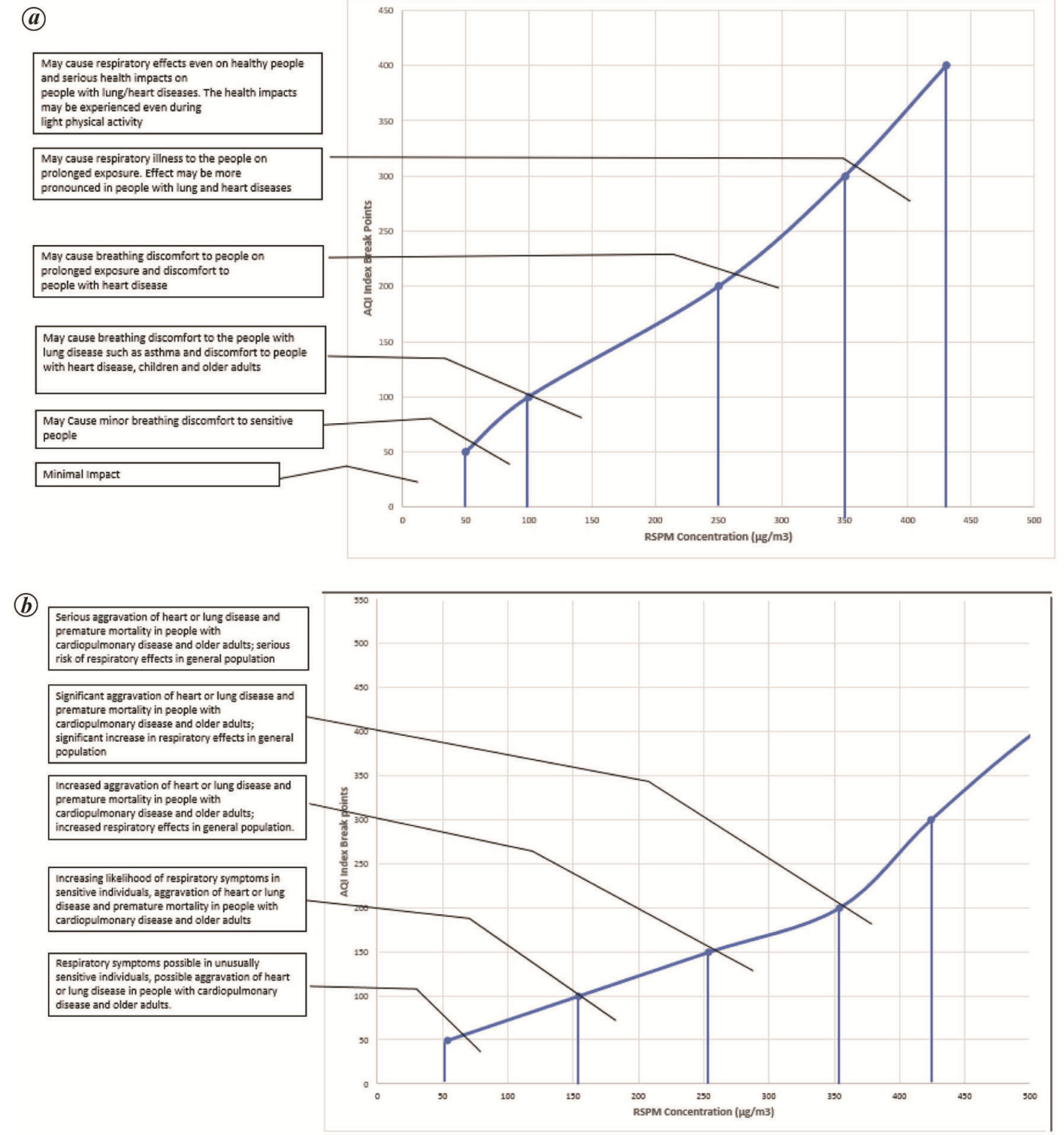

Figure 5. $\boldsymbol{a}$, IND-AQI sub-index break point and associated health effect statement for particulate matter (PM). $\boldsymbol{b}$, US-EPA-AQI sub-index break point and associated health effect statement for PM.

Figure 6 shows the prevalence percentage of AQI sub-index categories for different AQMS according to the IND-AQI system. It is observed that air quality varies widely among different stations. Air quality interpretation at different AQMS is discussed below.

The Nizamuddin monitoring station is located in the South Delhi district and represents the 'residential' category. Air quality at this station was observed to be in the 'poor' and 'very poor' categories about $50 \%$ of the time and in the 'moderate' category for $46 \%$ of the time.

The Siri Fort monitoring station is also located, in the South Delhi district and represents the 'residential' category. Here, air quality was observed to be in the 'moderate' category about $58 \%$ of the time, and in the 'poor' category about $36 \%$ of the time.
The NY School monitoring station is located in Southwest Delhi. Here $37 \%$ of the time air quality was observed to be in the 'poor', 'very poor' and 'severe' categories. Highest number of days (14\%) in the 'satisfactory' category of air quality was also observed in this station.

The Mayapuri monitoring station is also located in Southwest Delhi. Here $61 \%$ of the time air quality was in the 'poor' and above categories. 'Satisfactory' category of air quality was observed only $5 \%$ of the time, whereas 'moderate' category was observed $34 \%$ of the time.

Sahazada Bagh represents an industrial area and $32 \%$ of the period was observed with 'poor' category of air quality. Air quality at this station was in the 'moderate' category for $65 \%$ of the time. Air quality is also observed to be in 'very poor' or 'severe' category. 


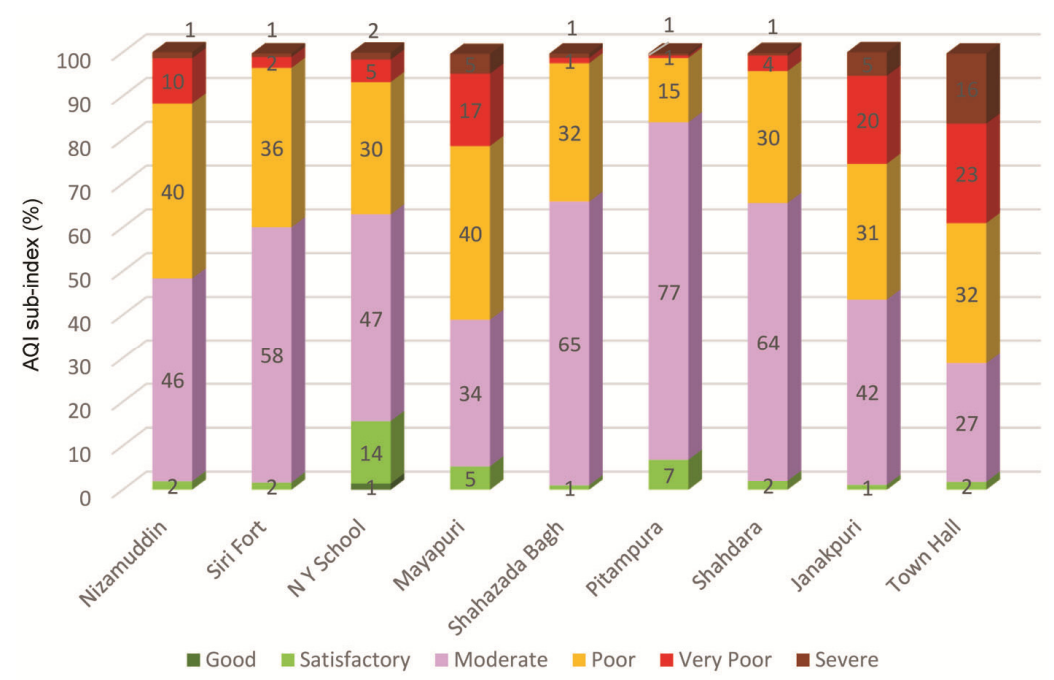

Figure 6. Spatial variation of air quality at different air quality monitoring stations.

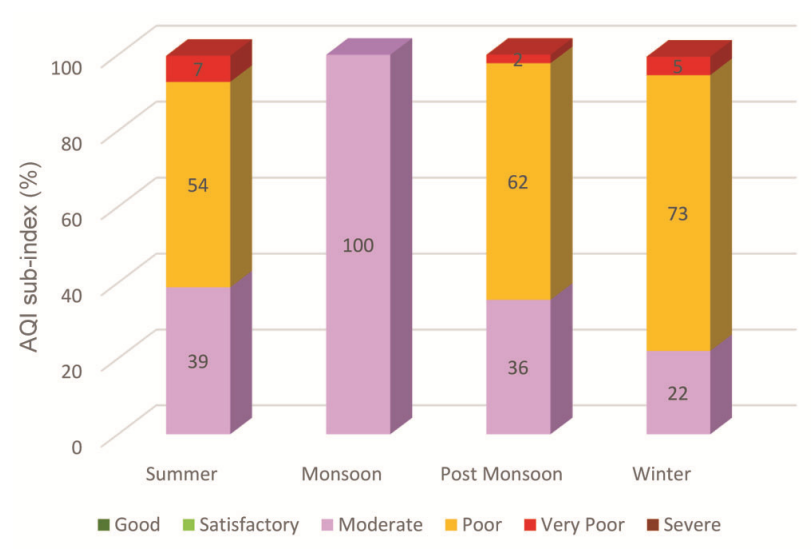

Figure 7. Frequency distribution of AQI sub-index categories during different seasons.

Though located in Northwest Delhi, the Pitampura monitoring station shows a sharp spatial deviation from the Sahazada Bagh monitoring station. Pitampura is a residential area located in the Northwest Delhi district. Here, air quality was predominantly observed to be in the 'moderate' category. However, it was also observed to reach the 'poor' category for $15 \%$ of the time. 'Satisfactory' category of air quality was observed $7 \%$ of the time.

Sahadara represents an industrial area and is located in East Delhi. This station shows a pattern almost similar to the Sahazada Bagh monitoring station for 'moderate' and 'poor' categories of air quality. Air quality reached the 'very poor' category about $3 \%$ of the time.

Janakpuri monitoring station is located in West Delhi district and represents the 'residential' category. Air quality at this station was observed to reach the 'poor' and 'very poor' category $31 \%$ and $20 \%$ of the time respectively. It reached the 'severe' category about $5 \%$ of the time.

Town Hall monitoring station is located in Central Delhi where air quality showed the highest number of days with 'severe' category. The population near Town Hall is exposed to the worst category of air quality among the monitoring stations. Air quality was observed to be in the 'poor' and above categories more than $71 \%$ of the time. 'Moderate' category of air quality was observed only $27 \%$ of the time.

The general characteristics of air quality during winter season (December-February) were observed to be detrimental for respiratory health when air quality was in the 'poor' category $73 \%$ of the time. Accumulation of pollutants during winter is due to reduced dispersal on account of low wind speed. Pollution build-up during summer season is due to dust storms and higher wind speed. During the rainy season (July-September), air quality was observed to be in the 'moderate' category all the time (lowest sub-index category was perceived during rainy season). During rainy season, low levels of pollution were observed due to wash-out effects of pollutants, high wind speed and shift in the general wind path. Postmonsoon (October-November) and summer (MarchJune) months also showed higher degree of pollution loads. Post-monsoon months had higher frequency of 'poor' air quality category (62\%) in comparison to summer months $(54 \%)$ due to reduced dispersion and burning of crop residues in the neighbouring states $^{25}$. Figure 7 shows seasonal fluctuation of air quality categories for Delhi.

Table 6 shows the linkage of AQI values with daily mortality count. It was observed that with per 100 units increase in AQI value, there was 3.7\% (95\% CI, 3.1-4.3) increase in daily non-trauma mortality rate. Also air quality displayed different effect estimates depending on age and sex. Impact estimate in the female population subgroup was more pronounced than in the male population subgroup. The effect estimate per 100 unit increase in AQI values for the female population subgroup was found to be $3.9 \%$ (95\% CI, 2.9-4.8) increase, whereas for the male population subgroup it was $3.7 \%$ (95\% CI, 2.94.4) increase in daily mortality values. Studies have also indicated that higher AQI levels have maximum impact 

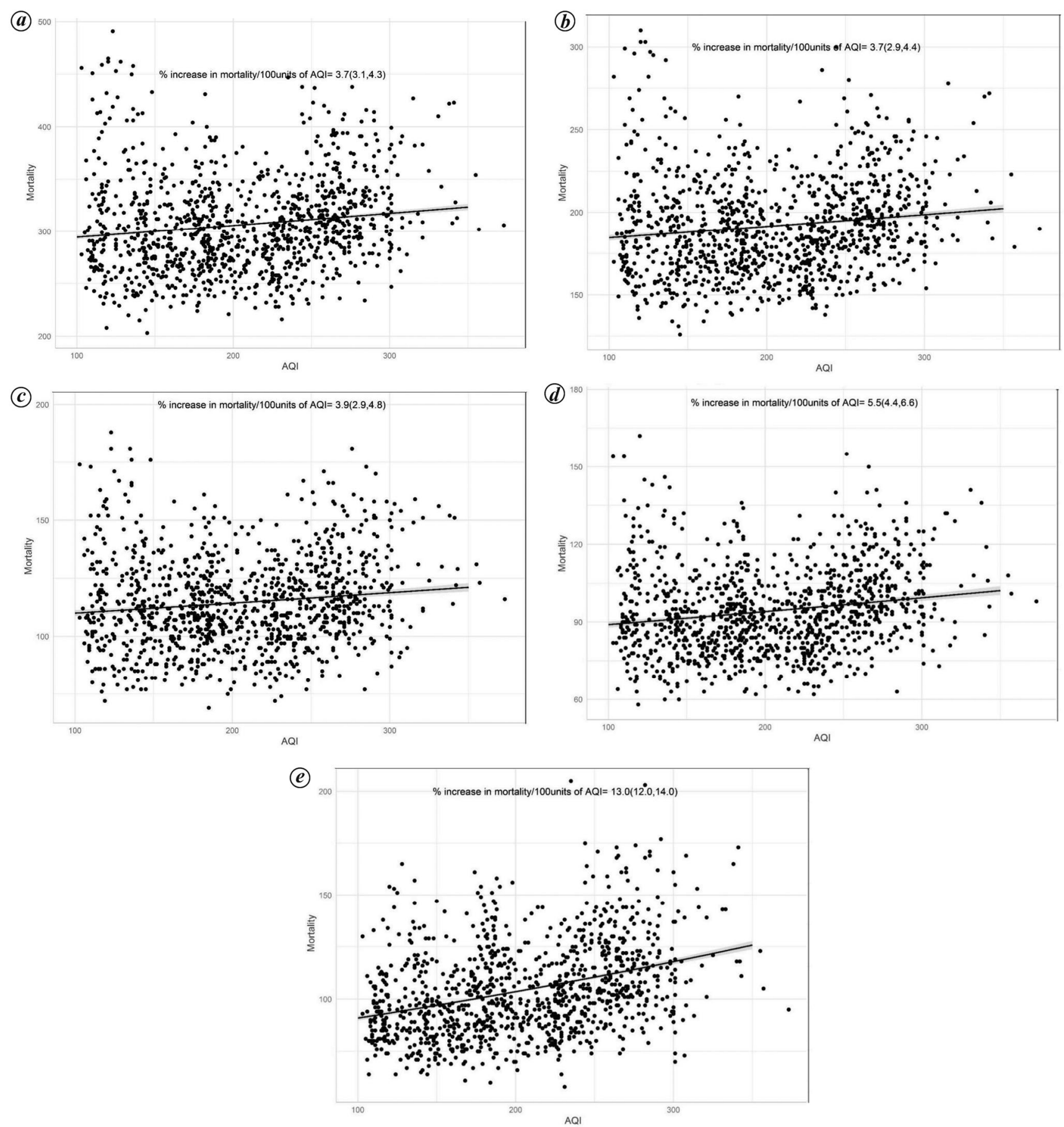

Figure 8. $\boldsymbol{a}$, Effect estimates of air quality on daily non-trauma mortality rate. $\boldsymbol{b}$, Effect estimates of air quality on daily non-trauma male mortality rate. $\boldsymbol{c}$, Effect estimates of air quality on daily non-trauma female mortality rate. $\boldsymbol{d}$, Effect estimates of air quality on daily non-trauma mortality rate in the population age group $45-64$ years. $\boldsymbol{e}$, Effect estimates of air quality on daily non-trauma mortality rate in the population age group $\geq 65$ years.

on the population age group of greater than 64 years $(13.0 \%, 95 \%$ CI, 12-14), whereas effect estimate for the population age group below 5 years and 5-44 years was found to be non-significant. In the age group 5-44 years, it there was 5.5\% (95\% CI 4.4-6.6) increase in daily mortality rates with per 100 unit increase in AQI values. Figure 8 shows the estimated increase in daily mortality rates with every 100 unit rise in AQI values.
The present study interprets air quality of Delhi using the AQI system and examines the inter-relationship of AQI sub-index values with daily-non-trauma mortality rates for the population of Delhi. Among the different stations, highest percentage in the 'poor' class of air quality was recorded at Mayapuri and Nizamuddin, whereas highest percentage of 'very poor' class was recorded at Janakpuri and Town Hall monitoring stations. Highest 
Table 6. Effect estimates of percentage increase in mortality values with per 100 units increase in AQI value

\begin{tabular}{lc}
\hline Model & $\begin{array}{c}\text { Percentage increase in mortality }(95 \% \mathrm{CI}) \\
\text { with per } 100 \text { units increase in AQI value }\end{array}$ \\
\hline Population & $3.7(3.1,4.3)$ \\
Sex: Male & $3.7(2.9,4.4)$ \\
Sex: Female & $3.9(2.9,4.8)$ \\
Age group : 45-64 years & $5.5(4.4,6.6)$ \\
Age group: $\geq 65$ years & $13.0(12.0,14.0)$ \\
\hline
\end{tabular}

percentage of days with 'severe' category of air quality was observed at the Town Hall monitoring station, while highest percentage of 'satisfactory' air quality was recorded at the NY School monitoring station. There was no 'good' category of air quality in any of the monitoring stations, except at NY School where 'good' category of air quality was observed $1 \%$ of the time during the whole study period. Percentage of poor air quality category was observed to be comparatively higher during winter season than the other seasons. The statistically significant association of the AQI values with non-trauma mortality rate was observed during the study period. It was observed that the female population subgroup and the population subgroup of age 65 years and above were more vulnerable to poor air quality. We have also linked the health effect estimates with AQI values.

We postulate that poor air quality is detrimental to human health for Delhi region. The study has many environmental as well as societal benefits. It will not only be beneficial for reducing the severity of air pollution, but also help in the overall improvement of public health awareness. Improved communication will help reduce public exposure to harmful effects of air quality. Also, better interpretation of air quality will help policymakers and planners to prioritize strategies air pollution management strategies for Delhi and other metro cities.

1. World Health Organization, WHO air quality guidelines for particulate matter, ozone, nitrogen dioxide and sulfur dioxide: global update 2005: summary of risk assessment. No. WHO/SDE/ PHE/OEH/06.02, WHO, Geneva, 2006.

2. Chen, R., Kan, H., Chen, B., Huang, W., Bai, Z., Song, G. and Pan, G., Association of particulate air pollution with daily mortality: The China air pollution and health effects study. Am. J. Epidemiol., 2012, 175(11), 1173-1181.

3. Mostofsky, E. et al., Modeling the association between particle constituents of air pollution and health outcomes. Am. J. Epidemiol., 2012, 176(4), 317-326.

4. Murray, C. J. and Lopez, A. D., Measuring the global burden of disease. N. Engl. J. Med., 2013, 369(5), 448-457.

5. Smith, K. R. et al., Millions dead: how do we know and what does it mean? Methods used in the comparative risk assessment of household air pollution. Annu. Rev. Public Health, 2014, 35, 185206.

6. WHO, Burden of disease from ambient air pollution for 2012. World Health Organization, Geneva, 2014.
7. Gurjar, B. R., Jain, A., Sharma, A., Agarwal, A., Gupta, P., Nagpure, A. S. and Lelieveld, J., Human health risks in megacities due to air pollution. Atmosp. Environ., 2010, 44(36), 4606-4613.

8. Balakrishnan, K., Ganguli, B., Ghosh, S., Sankar, S., Thanasekaraan, V., Rayudu, V. N. and Caussy, H., Part 1. Short-term effects of air pollution on mortality: results from a time-series analysis in Chennai, India. Research report, Health Effects Institute, Boston, USA, 2011, 157, pp. 7-44.

9. Rajarathnam, U., Sehgal, M., Nairy, S., Patnayak, R. C., Chhabra, S. K. and Ragavan, K. V., Part 2. Time-series study on air pollution and mortality in Delhi. Research report, Health Effects Institute, 2011, 157, pp. 47-74.

10. Dholakia, H. H., Bhadra, D. and Garg, A., Short term association between ambient air pollution and mortality and modification by temperature in five Indian cities. Atmos. Environ., 2014, 99, 168174.

11. Maji, S., Ahmed, S., Siddiqui, W. A. and Ghosh, S., Short term effects of criteria air pollutants on daily mortality in Delhi, India. Atmos. Environ., 2017, 150, 210-219.

12. Maji, S., Ghosh, S. and Ahmed, S., Association of air quality with respiratory and cardiovascular morbidity rate in Delhi, India. Int. J. Environ. Health Res., 2018, 28(5), 471-490.

13. Global Burden of Disease MAPs Working Group, Burden of disease attributable to major air pollution sources in India. Special report 21, 2018.

14. Government of Delhi, Annual report on registration of births and deaths in Delhi, Directorate of Economics and Statistics, New Delhi, 2010 (various issues).

15. Marlier, M. E., Jina, A. S., Kinney, P. L. and DeFries, R. S., Extreme air pollution in global megacities. Curr. Clim. Change Rep., 2016, 2(1), 15-27.

16. Environmental Protection Agency, Technical assistance document for the reporting of daily air quality - air quality index (AQI). Environmental Protection Agency, Office of Air Quality Planning and Standards, North Carolina, USA, 2013.

17. Central Pollution Control Board, National air quality index. Control of urban pollution series CUPS/82/2014-15, 2014; http:// cpcb.nic.in/FINAL-REPORT_AQI.pdf.

18. Gurjar, B. R., Ravindra, K. and Nagpure, A. S., Air pollution trends over Indian megacities and their local-to-global implications. Atmos. Environ., 2016, 142, 475-495.

19. Central Pollution Control Board, National ambient air quality monitoring series NAAQMS/35/2011-2012; 2012; www.cpcb.nic.in

20. Maji, S., Ahmed, S. and Siddiqui, W. A., Air quality assessment and its relation to potential health impacts in Delhi, India. Curr. Sci., 2015, 109(5), 902-909.

21. Government of Delhi, Delhi Statistical Handbook, Directorate of Economics and Statistics, New Delhi, 2001-2010.

22. General, Registrar. (2011), Census Commissioner, India. Census of India, 2000.

23. Cleveland, W. S. and Loader, C., Smoothing by local regression: principles and methods. In Statistical Theory and Computational Aspects of Smoothing, Physica-Verlag HD, New Jersey, UK, 1996, pp. 10-49.

24. James, G., Witten, D., Hastie, T. and Tibshirani, R., Linear model selection and regularization. In An Introduction to Statistical Learning, Springer, New York, USA, 2013, pp. 203-264.

25. Liu, T. et al., Seasonal impact of regional outdoor biomass burning on air pollution in three Indian cities: Delhi, Bengaluru, and Pune. Atmos. Environ., 2018, 172, 83-92.

Received 14 July 2019; revised accepted 2 July 2020

doi: $10.18520 / \mathrm{cs} / \mathrm{v} 119 / \mathrm{i} 6 / 1019-1026$ 